\title{
Comparison of Hybrid Electric Vehicle Power Electronics Cooling Options
}

Conference Paper NREL/CP-540-41886 January 2008

Michael O'Keefe and Kevin Bennion National Renewable Energy Laboratory

Presented at the Vehicle Power and Propulsion Conference 2007 Arlington, Texas

September 9-12, 2007

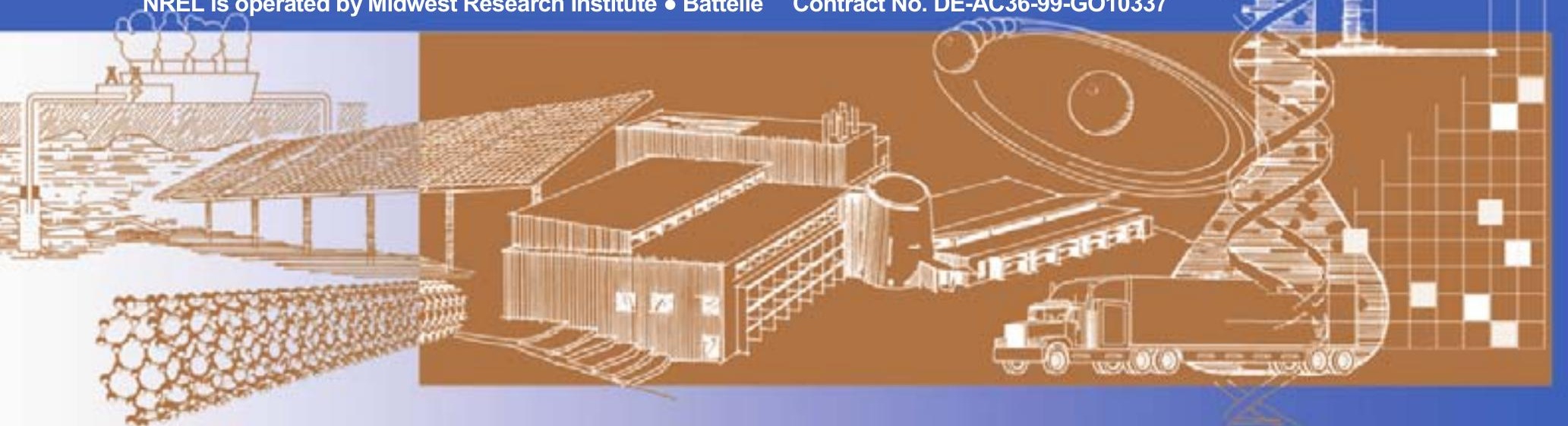




\section{NOTICE}

The submitted manuscript has been offered by an employee of the Midwest Research Institute (MRI), a contractor of the US Government under Contract No. DE-AC36-99G010337. Accordingly, the US Government and MRI retain a nonexclusive royalty-free license to publish or reproduce the published form of this contribution, or allow others to do so, for US Government purposes.

This report was prepared as an account of work sponsored by an agency of the United States government. Neither the United States government nor any agency thereof, nor any of their employees, makes any warranty, express or implied, or assumes any legal liability or responsibility for the accuracy, completeness, or usefulness of any information, apparatus, product, or process disclosed, or represents that its use would not infringe privately owned rights. Reference herein to any specific commercial product, process, or service by trade name, trademark, manufacturer, or otherwise does not necessarily constitute or imply its endorsement, recommendation, or favoring by the United States government or any agency thereof. The views and opinions of authors expressed herein do not necessarily state or reflect those of the United States government or any agency thereof.

Available electronically at http://www.osti.gov/bridge

Available for a processing fee to U.S. Department of Energy and its contractors, in paper, from:

U.S. Department of Energy

Office of Scientific and Technical Information

P.O. Box 62

Oak Ridge, TN 37831-0062

phone: 865.576 .8401

fax: 865.576 .5728

email: mailto:reports@adonis.osti.gov

Available for sale to the public, in paper, from:

U.S. Department of Commerce

National Technical Information Service

5285 Port Royal Road

Springfield, VA 22161

phone: 800.553 .6847

fax: 703.605.6900

email: orders@ntis.fedworld.gov

online ordering: http://www.ntis.gov/ordering.htm 


\title{
A Comparison of Hybrid Electric Vehicle Power Electronics Cooling Options
}

\author{
M. O'Keefe and K. Bennion
}

\begin{abstract}
This study quantifies the heat dissipation potential of three inverter package configurations over a range of control factors. These factors include coolant temperature, number of sides available for cooling, effective heat transfer coefficient, maximum semiconductor junction temperature, and interface material thermal resistance. Heat dissipation potentials are examined in contrast to a research goal to use $105^{\circ} \mathrm{C}$ coolant and dissipate $200 \mathrm{~W} / \mathrm{cm}^{2}$ heat across the insulated gate bipolar transistor and diode silicon area. Advanced double-sided cooling configurations with aggressive heat transfer coefficients show the possibility of meeting these targets for a $125^{\circ} \mathrm{C}$ maximum junction temperature, but further investigation is needed. Even with maximum tolerable junction temperatures of $200^{\circ} \mathrm{C}$, effective heat transfer coefficients of 5,000 to $10,000 \mathrm{~W} / \mathrm{m}^{2}-\mathrm{K}$ will be needed for coolant temperatures of $105^{\circ} \mathrm{C}$ or higher.
\end{abstract}

Index Terms - Inverters, Cooling, Semiconductor Device Thermal Management, Semiconductor Device Thermal Control

\section{INTRODUCTION}

$\mathrm{E}$ lectric drive technologies, which include electric machines (motors and generators) as well as the associated power electronics (inverters, DC-to-DC converters, etc.), represent a key enabling technology for advanced hybrid and electric vehicles that can reduce U.S. petroleum consumption. However, to penetrate the market, these electric drive technologies must enable vehicle solutions that are economically justifiable in large numbers to the average consumer. As critical components of the electric drive system are made smaller, lighter, and more cost effective, heat removal becomes an increasing challenge.

To successfully integrate advanced power electronics concepts into vehicle applications, the thermal limitations of the semiconductor devices must be addressed. Critical semiconductor components in the inverter (insulated gate

Manuscript received August 6, 2007. This manuscript has been authored by Midwest Research Institute under Contract No. DE-AC36-99GO10337 with the U.S. Department of Energy. The United States Government retains and the publisher, by accepting the article for publication, acknowledges that the United States Government retains a non-exclusive, paid-up, irrevocable, world-wide license to publish or reproduce the published form of this manuscript, or allow others to do so, for United States Government purposes.

M. O'Keefe is with the National Renewable Energy Laboratory at 1617 Cole Blvd. MS 1633, Golden, CO 80401 USA (phone: 303-275-4268; fax: 303-275-4415; e-mail: michael_okeefe@nrel.gov).

$\mathrm{K}$. Bennion is also with the National Renewable Energy Laboratory in Golden, CO USA. bipolar transistors [IGBTs] and diodes) are sensitive to temperature and must operate below fixed temperature limits. Device efficiency decreases as temperature increases, and $125^{\circ} \mathrm{C}$ is a nominal upper temperature limit for silicon devices. The vehicle must achieve its performance requirements as it operates within this thermal limitation. In addition, the goals for maintaining system reliability and reducing the system cost, volume, and weight are always present.

Addressing these objectives requires investigation into multiple technology pathways that involve materials and thermal control. Silicon carbide (SiC) materials offer the promise of operation at significantly elevated temperatures, but whether the entire inverter system can tolerate these elevated temperatures remains to be seen. In the area of thermal control for power electronics, multiple technologies and configurations are under investigation. For conventional inverters, the thermal interface material (TIM) that thermally joins the inverter baseplate to a heat sink has long been recognized as a source of high thermal resistance. This leads to the development of advanced TIMs with drastically reduced thermal resistance. Other concepts decrease the overall thermal resistance by eliminating the need for TIMs altogether. Finally, double-sided power electronics cooling concepts that significantly increase the heat sink area per package have been commercialized by a major automotive original equipment manufacturer [1].

There is a need for system-level analysis that compares the thermal performance of these conventional and new inverter package designs. This paper begins to address this need. The results highlight differences in thermal performance of options for the thermal control of inverters.

The U.S. Department of Energy (DOE) Advanced Power Electronics and Electric Machines (APEEM) R\&D team develops power electronics technologies for fuel cell and hybrid electric vehicles (HEVs). The APEEM team consists of members at DOE and researchers at the national laboratories who work through the FreedomCAR and Fuels Partnership with the U.S. automotive industry. The authors are interested in exploring thermal control technology options, keeping in mind the cooling rates that will be needed to overcome the thermal barriers associated with the next generation of power electronics technologies being developed through the FreedomCAR and Fuels Partnership.

One research goal under the FreedomCAR and Fuels Partnership is to use only one cooling loop for an HEV, and 
allows for a cost saving of $\$ 150$ to $\$ 200$ for an HEV such as the Toyota Prius [2]. This is a significant cost considering the cost targets for the entire electric traction system are $\$ 660$ by 2015 and $\$ 440$ by 2020 . A single cooling loop necessitates cooling the power electronics, electric machines, and internal combustion engine with one coolant. The power electronics inverter would thus have to tolerate inlet coolant temperatures up to $105^{\circ} \mathrm{C}[3]$.

\section{PROCEDURE}

\section{A. Finite Element Analysis Modeling}

This study examines three package designs over a design space of variable coolant temperatures, variable TIM resistance, variable maximum semiconductor junction temperatures, and variable effective convective heat transfer coefficients. The term package includes one IGBT, one diode, and the associated materials to thermally manage the IGBT and diode. An isometric view from CAD of the baseline package is given in Fig. 1.

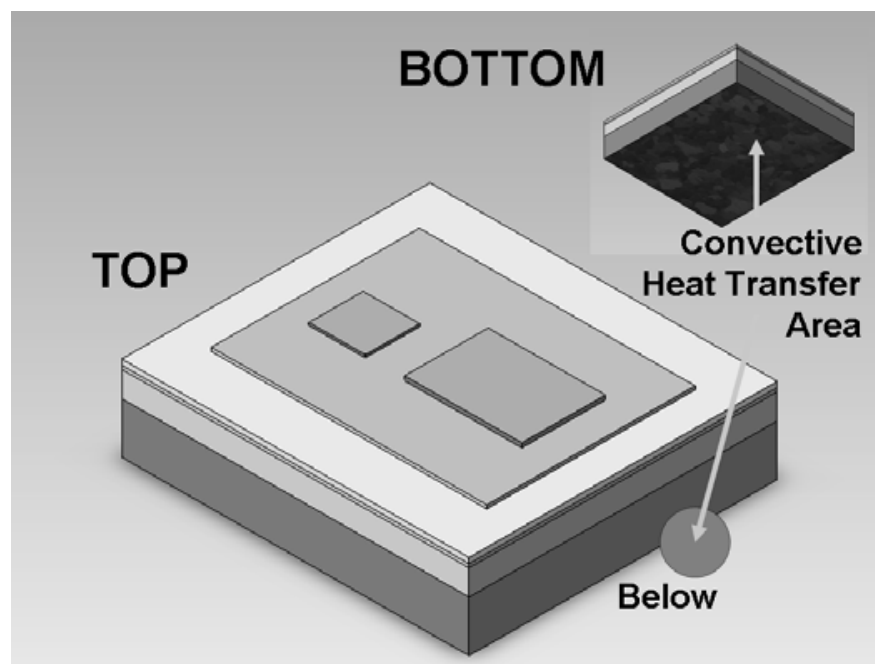

Fig. 1. Isometric view of the baseline (BL) package. The area for convective heat transfer is held constant between package configurations and is indicated in the figure.

TABLE I

CONFIGURATION KEY

\begin{tabular}{|c|c|}
\hline Name & Configuration \\
\hline BASELINE (BL) & $\begin{array}{l}\text { Power semiconductor: } \mathrm{Si} \\
\text { Substrate: } \mathrm{DBC} \text { with AlN } \\
\text { Baseplate: } \mathrm{Cu} \\
\text { TIM: } 5,100 \mathrm{~mm}^{2} \mathrm{~K} / \mathrm{W} \\
\text { Heat sink: } \mathrm{Al}\end{array}$ \\
\hline $\begin{array}{l}\text { DIRECT } \\
\text { BACKSIDE } \\
\text { COOLING } \\
\text { (DBSC) }\end{array}$ & $\begin{array}{l}\text { Power semiconductor: } \mathrm{Si} \\
\text { Substrate: DBC with AlN } \\
\text { Baseplate: None } \\
\text { TIM: None } \\
\text { Heat sink: None }\end{array}$ \\
\hline $\begin{array}{l}\text { INTEGRATED } \\
\text { HEAT SINK } \\
\text { (IHS) }\end{array}$ & $\begin{array}{l}\text { Power semiconductor: } \mathrm{Si} \\
\text { Substrate: } \mathrm{DBC} \text { with AlN } \\
\text { Baseplate: } \mathrm{Cu} \text { (baseplate }=\text { heat sink) } \\
\text { TIM: None } \\
\text { Heat sink: None }\end{array}$ \\
\hline
\end{tabular}

TABLE II

MATERIAL KEY

\begin{tabular}{|l|l|}
\hline Index & Material \\
\hline 1 & Diode: $\mathrm{Si}$ \\
\hline 2 & IGBT: $\mathrm{Si}$ \\
\hline 3 & DBC top layer: $\mathrm{Cu}$ \\
\hline 4 & DBC substrate layer: $\mathrm{AlN}$ \\
\hline 5 & DBC bottom layer: $\mathrm{Cu}$ \\
\hline 6 & Baseplate: $\mathrm{Cu}$ \\
\hline 7 & Heat sink: $\mathrm{Al}$ \\
\hline
\end{tabular}

TABLE III

PACKAGE GEOMETRY

\begin{tabular}{|l|l|}
\hline & BASELINE \\
\hline IGBT area $\left(\mathrm{cm}^{2}\right)$ & $1.372 \times 0.978=1.342$ \\
\hline Diode area $\left(\mathrm{cm}^{2}\right)$ & $0.660 \times 0.635=0.419$ \\
\hline DBC top area $\left(\mathrm{cm}^{2}\right)$ & $3.226 \times 2.438=7.865$ \\
\hline Heat sink convective Area $(1 \mathrm{Side})\left(\mathrm{cm}^{2}\right)$ & 14.64 \\
\hline IGBT thickness $(\mathrm{cm})$ & 0.051 \\
\hline Diode thickness $(\mathrm{cm})$ & 0.032 \\
\hline DBC top thickness $(\mathrm{cm})$ & 0.041 \\
\hline Substrate thickness $(\mathrm{cm})$ & 0.064 \\
\hline DBC bottom thickness $(\mathrm{cm})$ & 0.041 \\
\hline Baseplate thickness $(\mathrm{cm})$ & 0.300 \\
\hline Heat sink thickness $(\mathrm{cm})$ & 0.600 \\
\hline
\end{tabular}

Each package configuration considered in this study appears in Table I. In addition, double-sided concepts of each configuration were considered. The baseline package is representative of a modern HEV inverter cooling system. Because of the space considerations associated with packaging an inverter in a vehicle, it is unlikely that the two-dimensional projected area available to each package would be increased. In fact, the trend is to further decrease the inverter's footprint. Thus, increased package footprints were not considered. The two other package configurations considered here include a direct backside cooling (DBSC) concept and an integrated heat-sink (IHS) concept. The DBSC is under evaluation in prototype form. In the DBSC concept, the backside of the Direct Bond Copper (DBC) layer is opened up to direct contact with the convective heat transfer surface. For the IHS concept, the baseplate functions as a heat sink. Both concepts eliminate the need for TIMs. However, the reliability of these concepts is still under investigation (for example, with regard to differential thermal expansion problems). Another concept not considered here is the ability to use air jets directly on the chip (i.e., even less packaging than the DBSC concept). Double-sided air cooling may be an option as well.

The package configurations are shown in Figs. 3 to 5. Table II lists the materials for the package layers. The CAD software "SolidWorks" was used to construct all the package configurations, which were then imported into the software "ANSYS Workbench" for thermal analysis using the Finite Element Analysis (FEA) methodology (see Fig. 2). The area open to convective heat transfer for each package configuration was fixed to $14.64 \mathrm{~cm}^{2}$. Double-sided cooling concepts have twice that area available. The thicknesses of layers and area cross sections of the package components are provided in Table III. 


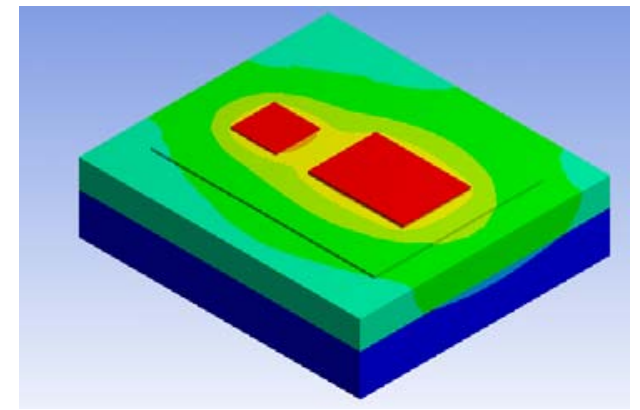

Fig. 2. Screenshot of temperature field on ANSYS FEA model of baseline package. Effective heat transfer is $15,000 \mathrm{~W} / \mathrm{m}^{2}-\mathrm{K}$, coolant temperature $70^{\circ} \mathrm{C}$.

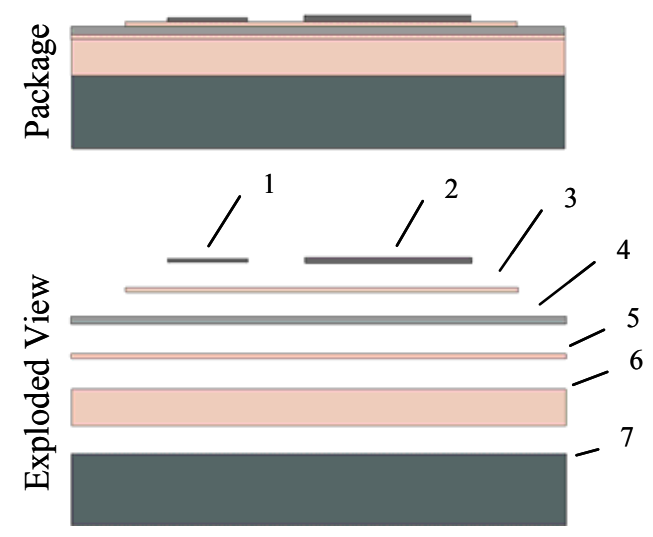

Fig. 3. BL package configuration

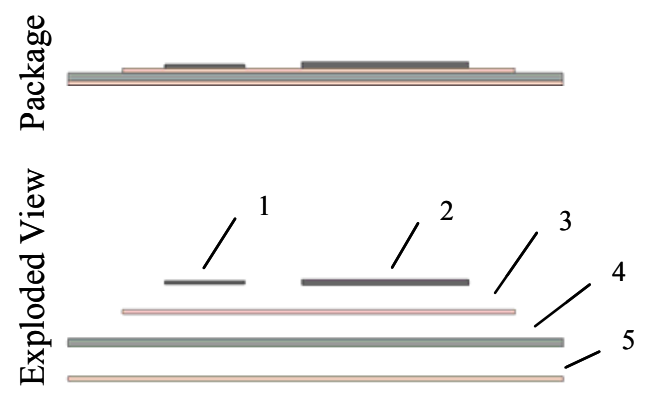

Fig. 4. DBSC package configuration

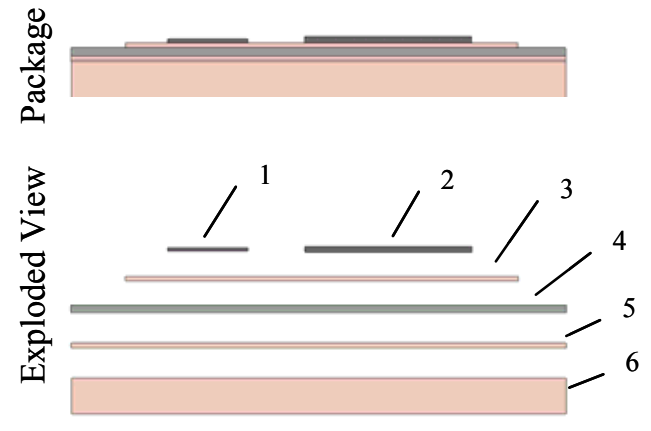

Fig. 5. Baseline with IHS package configuration

Since the baseline package requires a TIM, it uses a range of thermal resistances that range from $5 \mathrm{~mm}^{2}-\mathrm{K} / \mathrm{W}$, representing an advanced TIM to $100 \mathrm{~mm}^{2}-\mathrm{K} / \mathrm{W}$, representing a modern TIM. These are total resistances that include bulk resistance of the TIM and contact resistances. The range of these estimates was chosen based on preliminary measurements of actual TIMs from NREL's Advanced Power Electronics laboratory. TIM resistances of $100 \mathrm{~mm}^{2}-\mathrm{K} / \mathrm{W}$ and more have been observed; the value of $5 \mathrm{~mm}^{2}-\mathrm{K} / \mathrm{W}$ is a stretch goal used here to explore the potential of advanced TIMs.

The convective heat transfer coefficient applied to the area open to convective heat transfer for each package is an effective coefficient that corresponds to the $2 \mathrm{D}$ projected area of the heat sink shown in Fig. 1. Area enhancement and area enhancement efficiency are incorporated into the effective convection coefficient. Effective convection coefficients from $200 \mathrm{~W} / \mathrm{m}^{2}-\mathrm{K}$ represent conventional forced air cooling up to $80,000 \mathrm{~W} / \mathrm{m}^{2}-\mathrm{K}$, which represent advanced concepts such as two-phase cooling with area enhancement are examined in this study. Even higher effective heat transfer coefficients are theoretically possible. The authors chose $80,000 \mathrm{~W} / \mathrm{m}^{2}-\mathrm{K}$ as a stretch goal to examine for this study. For each convection coefficient, the coolant temperatures are swept from $25^{\circ} \mathrm{C}$ (representing air and refrigerant coolants) up to $125^{\circ} \mathrm{C}$. However, these are bulk coolant temperatures that are available at the heat-sink directly below the package, as opposed to coolant inlet temperatures.

The effective overall convection coefficient is related to an unadjusted heat transfer coefficient as follows:

$$
U=h \cdot A E \cdot \eta
$$

$U$ is the effective convection coefficient, $\mathrm{AE}$ is the area enhancement ratio (the ratio of total convective surface area to the baseplate area), and $\eta$ is an efficiency term that gives the effective use of the area enhancement. Fig. 6 shows how $U$ relates to $h$ and the term $A E \cdot \eta$. Three examples appear in Fig. 6. Point A corresponds to a submerged liquid jet that has a heat transfer coefficient of $65,000 \mathrm{~W} / \mathrm{m}^{2}-\mathrm{K}$ over the target surface with no area enhancement. Thus, the effective heat transfer coefficient is $65,000 \mathrm{~W} / \mathrm{m}^{2}-\mathrm{K}$. Point B corresponds to a pin fin heat exchanger with $20,000 \mathrm{~W} / \mathrm{m}^{2}-\mathrm{K}$ heat transfer coefficient and an area enhancement of 3 with pin efficiency of $50 \%$. This results in an effective heat transfer coefficient of $30,000 \mathrm{~W} / \mathrm{m}^{2}-\mathrm{K}$. Point $\mathrm{C}$ corresponds to air cooling over a finned heat exchanger with an estimated area enhancement of 6 and a fin efficiency of $50 \%$ with a convective heat transfer coefficient of $80 \mathrm{~W} / \mathrm{m}^{2}-\mathrm{K}$ over the fins. This is equivalent to an effective overall heat transfer coefficient of $240 \mathrm{~W} / \mathrm{m}^{2}-\mathrm{K}$ applied to our package model's area for convective heat transfer. 


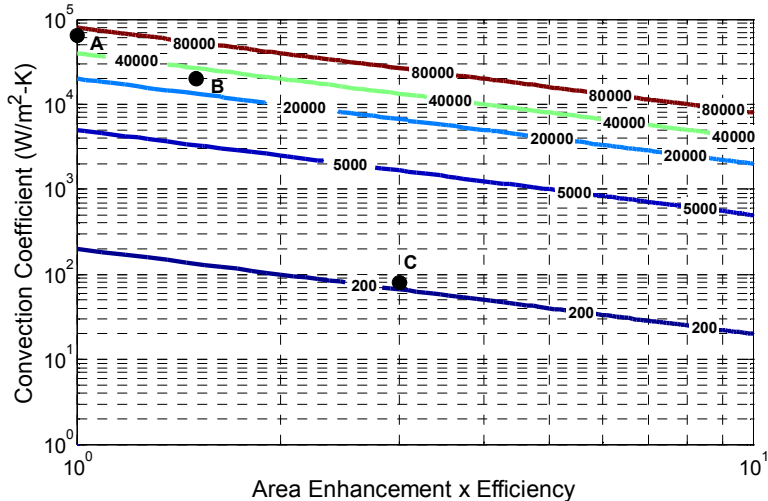

Fig. 6. Relationship of convection coefficient and area enhancement to effective convection coefficient. Three example points are displayed on the chart. Point A is for a single phase submerged liquid jet at $12 \mathrm{~m} / \mathrm{s}$ with no area enhancement. Point B corresponds to pin-fin liquid cooling with some area enhancement. Point $\mathrm{C}$ corresponds to forced air cooling with fins.

The analysis assumed maximum junction temperatures of $125^{\circ} \mathrm{C}$ and $200^{\circ} \mathrm{C}$. The temperature of $200^{\circ} \mathrm{C}$ was chosen to represent a high temperature tolerance $\mathrm{SiC}$ inverter design limited by non-SiC components [4], [5].

\section{B. Assumptions}

The following is a discussion of key assumptions used in this study with their potential implications. The assumptions relate to coolant temperature, solder layers, semiconductor boundary conditions, heat transfer coefficients, and doublesided cooling configurations. In addition, a brief overview of heat dissipation targets is included to put the results in the proper context.

The coolant temperature used in the analysis must be viewed in relation to the investigated package. All the results were examined at the level of a single package that consists of one IGBT and one diode. Interactions between multiple packages on a single inverter are not considered. The bulk coolant temperature referenced in this paper is the coolant temperature available to that package locally at its convective boundary layer. This coolant temperature will likely be warmer than the coolant inlet temperature unless special accommodations are made in the design (e.g., parallel channels).

In this study, the resistances of solder joints were neglected. A comparison was made between an FEA model with solder joint resistance modeled and without to determine the effect of this assumption on heat dissipation prediction. The error introduced by neglecting these resistances was less than $3 \%$, which is acceptable for the purposes of this comparative study.
TABLE IV

COMPARISON OF BOUNDARY CONDITIONS ON BASELINE MODEL

\begin{tabular}{|l|l|l|}
\hline & $\begin{array}{l}\text { Isothermal } \\
125^{\circ} \mathrm{C} \\
\text { Boundary } \\
\text { Condition }\end{array}$ & $\begin{array}{l}\text { Constant Flux } \\
\text { Boundary } \\
\text { Condition }\end{array}$ \\
\hline TIM thermal resistance $\left(\mathrm{mm}^{2}-\mathrm{K} / \mathrm{W}\right)$ & 30 & 30 \\
\hline Convection coefficient $\left(\mathrm{W} / \mathrm{m}^{2}-\mathrm{K}\right)$ & 15,000 & 15,000 \\
\hline Coolant temperature $\left({ }^{\circ} \mathrm{C}\right)$ & 70 & 70 \\
\hline IGBT heat generation $(\mathrm{W})$ & 216.32 & 216.32 \\
\hline Diode heat generation $(\mathrm{W})$ & 107.55 & 107.55 \\
\hline Peak IGBT face temperature $\left({ }^{\circ} \mathrm{C}\right)$ & 125 & 131.11 \\
\hline Minimum IGBT face temperature $\left({ }^{\circ} \mathrm{C}\right)$ & 125 & 115.49 \\
\hline Average IGBT face temperature $\left({ }^{\circ} \mathrm{C}\right)$ & 125 & 125.16 \\
\hline Peak diode face temperature $\left({ }^{\circ} \mathrm{C}\right)$ & 125 & 131.01 \\
\hline Minimum diode face temperature $\left({ }^{\circ} \mathrm{C}\right)$ & 125 & 115.97 \\
\hline Average diode face temperature $\left({ }^{\circ} \mathrm{C}\right)$ & 125 & 124.98 \\
\hline
\end{tabular}

A constant temperature boundary condition for the semiconductor devices in all package configurations was applied for this analysis. This assumption allowed quick and consistent comparison of package designs. A comparison of the isothermal boundary condition to that of a constant flux boundary condition is shown in Table V. The constant flux boundary condition results in a temperature distribution across the semiconductor device surface as opposed to an isothermal condition. The average temperature of the constant flux boundary conditions is approximately the same as that of the isothermal boundary condition. However, the maximum temperature of the device is approximately $6^{\circ} \mathrm{C}$ higher for the constant flux boundary condition for the same overall heat dissipation under the simulated conditions. The implication is that the heat fluxes shown in this study should be viewed as upper bounds (i.e., overestimates). In addition to using the isothermal boundary condition for the semiconductor devices, the junction temperatures for the IGBT and the diode were set to the maximum. This is a conservative assumption, as the IGBT and diode would probably not be at their maximum junction temperatures at the same time.

As previously discussed, the exact mechanism for the convective heat transfer is left unspecified in the analysis. Instead, a range of values representing the effective convection coefficient at the package model's convective boundary layer is used. To make comparison easier, each package configuration has the same constant area for convective heat transfer. The remainder of each package is assumed to have an adiabatic boundary condition with no thermal interaction with other packages.

The double-sided heat transfer is addressed by assuming the package designs are mirrored for a double-sided cooling configuration. This assumes the same heat transfer coefficient and bulk coolant temperature are available on both sides of the package and that there is an equivalent thermal conductance in both directions. The maximum heat dissipation rate for the double-sided package is assumed to be twice that of the singlesided package, because the area for convective heat transfer is doubled.

To place the results in context, the required amount of heat dissipation per package for a next-generation advanced 
inverter approximately the same size as the Toyota Prius 50 $\mathrm{kW}$ traction motor inverter is assumed at $200 \mathrm{~W} / \mathrm{cm}^{2}$. This has been an accepted goal for the FreedomCAR program thus far, but it may need to be revisited based on recent technological progress. This value of $200 \mathrm{~W} / \mathrm{cm}^{2}$ will serve as a heat flux dissipation target to orient the reader when comparing the heat transfer technologies.

\section{RESULTS}

Figs. 7 to 9 summarize the heat flux dissipation performance by package concept by effective convection coefficient. Horizontal dashed lines in the figures indicate our heat flux dissipation goal. In terms of packaging concepts, the results from the IHS and DBSC concepts are quite similar. The DBSC has higher dissipation rates than the IHS concept when higher convection coefficients are used. In contrast, the IHS design has slightly better heat dissipation potential at lower convection coefficients because of more effective heat spreading and area use. The width of the region for the baseline results is due to changes in TIM thermal resistance. Clearly, the TIM resistance is significant for the baseline results, especially at higher convective heat transfer values.

The double-sided cooling concept shows great potential, but more thorough analysis is needed to confirm these findings. Fig. 13 in Sakai et al. [1] seems to indicate at least a potential to double the heat transfer with a double-sided concept, although isolating the impact of double-sided cooling from their reported results is difficult, as many changes were made between their baseline and current design.

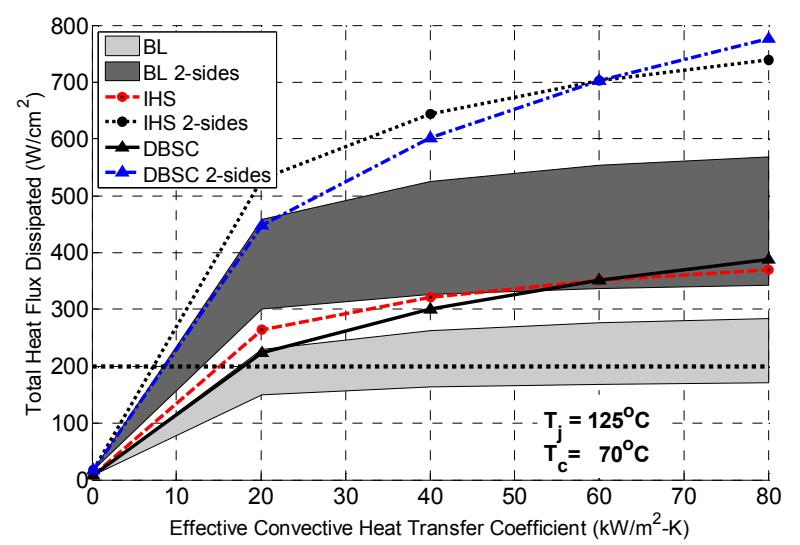

Fig. 7. Heat dissipation rates for package configurations by effective convective heat transfer coefficient. Maximum junction temperature is $125^{\circ} \mathrm{C}$ and coolant temperature is $70^{\circ} \mathrm{C}$. The horizontal dashed line represents the heat flux dissipation goal. The widths of the regions for the BL model are due to differing values of TIM thermal resistance.

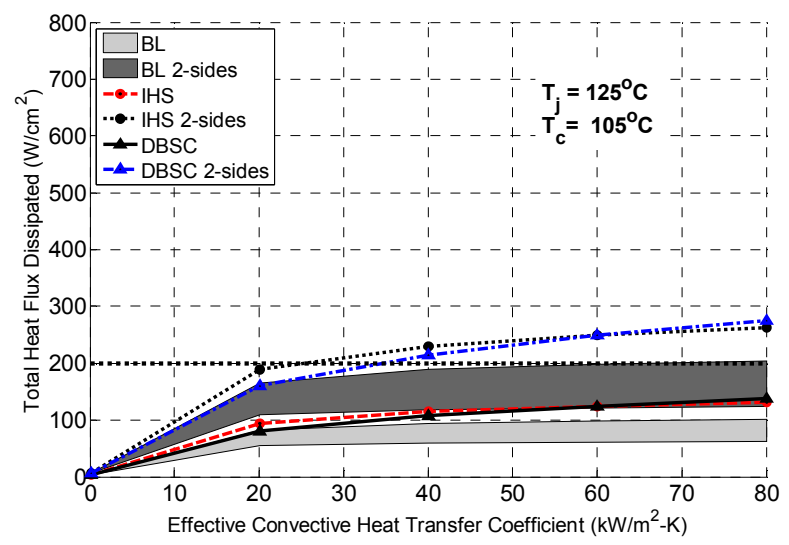

Fig. 8. Heat dissipation rates for package configurations by effective convective heat transfer coefficient. Maximum junction temperature is $125^{\circ} \mathrm{C}$ and coolant temperature is $105^{\circ} \mathrm{C}$. The horizontal dashed line represents the heat flux dissipation goal. The widths of the regions for the BL model are due to differing values of TIM thermal resistance.

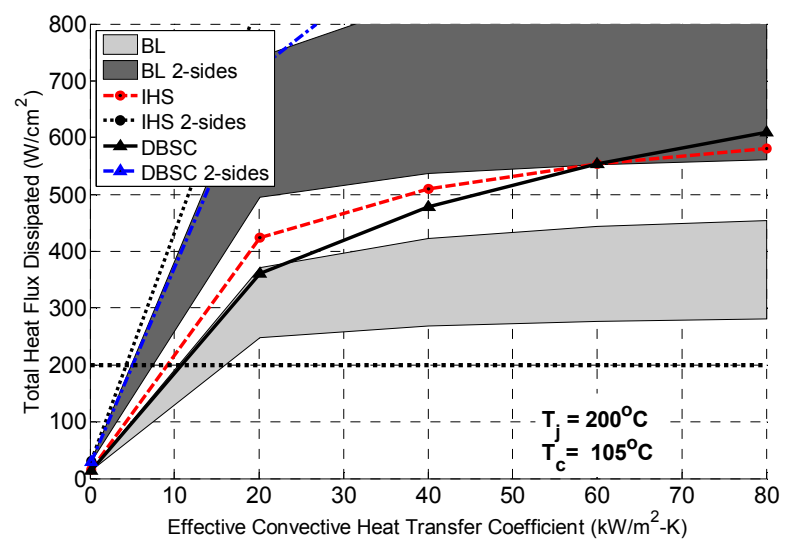

Fig. 9. Results for package configurations by effective convective heat transfer coefficient. Maximum junction temperature is $200^{\circ} \mathrm{C}$ and coolant temperature is $105^{\circ} \mathrm{C}$. The horizontal dashed line represents the heat flux dissipation goal. The widths of the regions for the BL model are due to differing values of TIM thermal resistance.

Maintaining the required $125^{\circ} \mathrm{C}$ junction temperature limit with coolant temperatures of at least $105^{\circ} \mathrm{C}$ is difficult. A comparison between Figs. 7 and 8 highlights this challenge. No single-sided concepts among the configurations considered meet the heat flux goal under these conditions.

When the maximum allowable junction temperature is increased to $200^{\circ} \mathrm{C}$, all the concepts show the ability to meet the heat dissipation flux goal with $105^{\circ} \mathrm{C}$ coolant (Fig. 9). Even under these favorable conditions, however, the package configurations considered indicate that effective heat transfer coefficients of $5,000 \mathrm{~W} / \mathrm{m}^{2}-\mathrm{K}$ to $15,000 \mathrm{~W} / \mathrm{m}^{2}-\mathrm{K}$ are required for single-sided designs to meet the heat flux dissipation goal. Cooling strategies such as conventional forced air cooling with fins and free convection to air may be challenged to provide sufficient convective cooling under these conditions. Investigations with forced air cooling are being investigated, and further analysis is needed.

Fig. 10 shows how heat dissipation changes for the baseline configuration as a function of bulk coolant temperature for several convective heat transfer conditions. The maximum 
junction temperature is assumed to be $125^{\circ} \mathrm{C}$. In Fig. 10, the widths of the bands are due to the effect of sweeping TIM thermal resistance. Higher heat flux dissipations are possible with lower TIM thermal resistance. Systems that use a pinfinned forced liquid cooling plate would have an estimated $\mathrm{U}$ value of $15,000 \sim 30,000 \mathrm{~W} / \mathrm{m}^{2}-\mathrm{K}$ and use $60^{\circ}$ to $70^{\circ} \mathrm{C}$ coolant. Heat flux dissipation rates are near zero for $\mathrm{U}$ values of 200 $\mathrm{W} / \mathrm{m}^{2}-\mathrm{K}$.

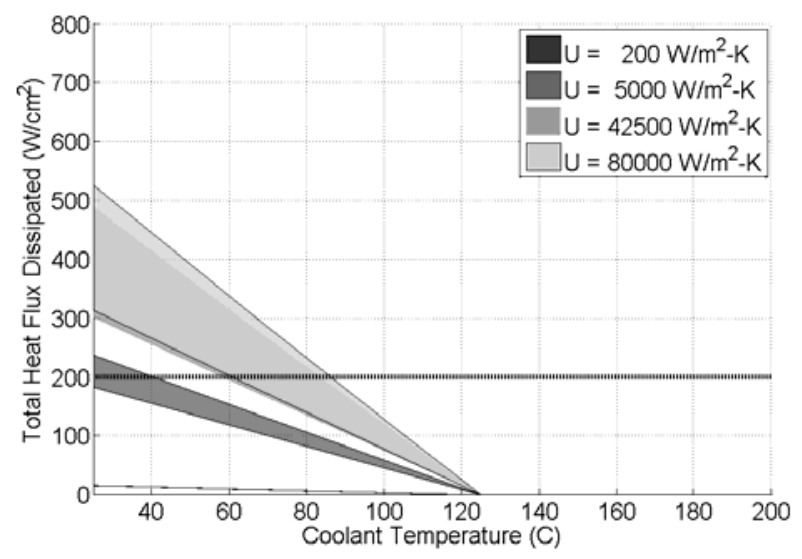

Fig. 10. Heat dissipation for the single-sided BL package configuration with a maximum junction temperature of $125^{\circ} \mathrm{C}$ as a function of bulk coolant temperature, convection coefficient, and TIM resistance. Three areas are depicted on the graph with differing effective convective heat transfers coefficients. The width of the bands is due to the TIM resistance, which is swept from $100 \mathrm{~mm}^{2}-\mathrm{K} / \mathrm{W}$ down to $5 \mathrm{~mm}^{2}-\mathrm{K} / \mathrm{W}$. The dashed horizontal line indicates the target heat dissipation rate of $200 \mathrm{~W} / \mathrm{cm}^{2}$.

A dashed horizontal line in Fig. 10 indicates the cooling target of $200 \mathrm{~W} / \mathrm{cm}^{2}$ across the IGBT and diode area. The challenge of cooling with $105^{\circ} \mathrm{C}$ and greater coolant temperatures coupled with a maximum junction temperature of $125^{\circ} \mathrm{C}$ is again apparent. Even under very aggressive effective convection heat transfer conditions, there is not enough driving temperature potential to allow significant heat dissipation. Fig. 11 shows the same baseline configuration, but this time with a maximum junction temperature of $200^{\circ} \mathrm{C}$. Although there are now solutions for use of $105^{\circ} \mathrm{C}$ coolant, an effective heat transfer coefficient above approximately $5,000 \mathrm{~W} / \mathrm{m}^{2}-\mathrm{K}$ will be required.

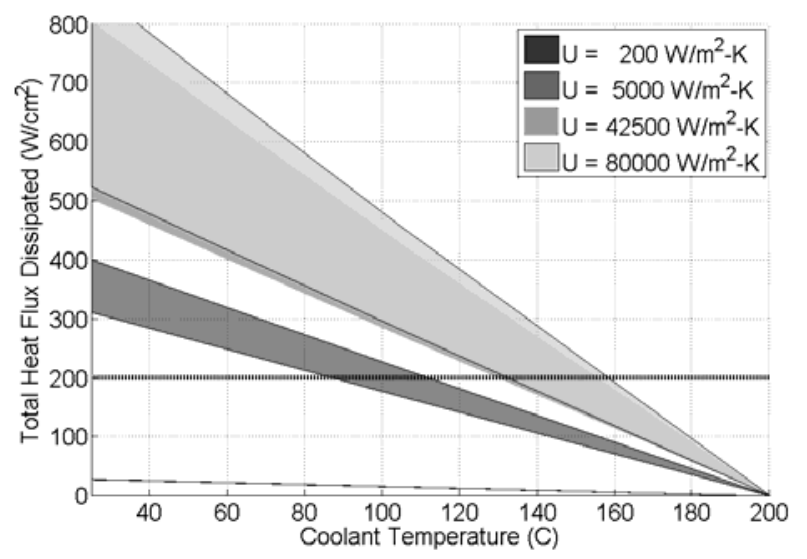

Fig. 11. Heat dissipation for the single-sided BL package configuration with a maximum junction temperature of $200^{\circ} \mathrm{C}$ as a function of bulk coolant temperature, convection coefficient, and TIM resistance.

Figs. 12 and 13 present the total heat dissipation for the onesided IHS package configuration with $125^{\circ} \mathrm{C}$ and $200^{\circ} \mathrm{C}$ maximum junction temperatures, respectively. Again, the challenge of cooling with $105^{\circ} \mathrm{C}$ or higher coolant temperature and a maximum junction temperature of only $125^{\circ} \mathrm{C}$ is apparent. Even with $200^{\circ} \mathrm{C}$, effective heat transfer coefficients of about $5,000 \mathrm{~W} / \mathrm{m}^{2}-\mathrm{K}$ will be needed. This is approximately an order of magnitude higher convective cooling coefficient than that available from free convection [6]. For this reason, NREL's air cooling research focuses on forced air convection solutions. Conventional air cooling with underhood air will not likely achieve the goal, but aggressive air cooling with enhanced surface area and outside air may have potential.

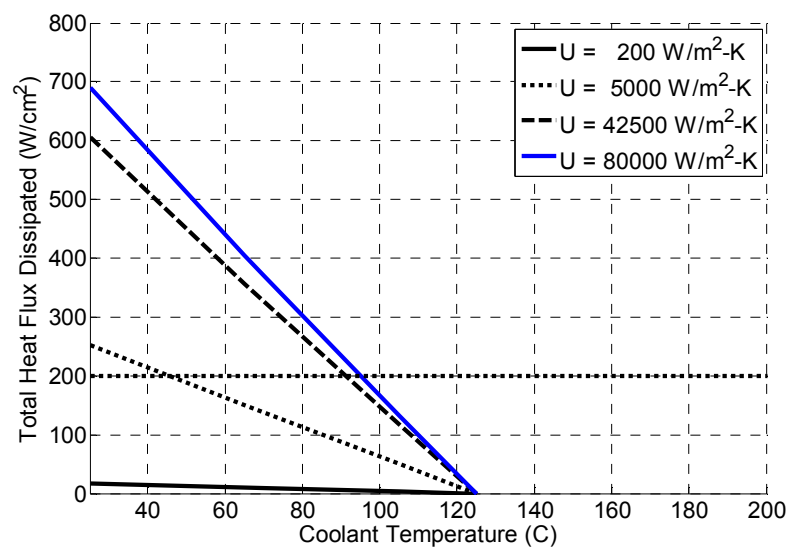

Fig. 12. Heat dissipation for the single-sided IHS package configuration with a maximum junction temperature of $125^{\circ} \mathrm{C}$ as a function of bulk coolant temperature and convection coefficient. This configuration does not employ any TIMs. 


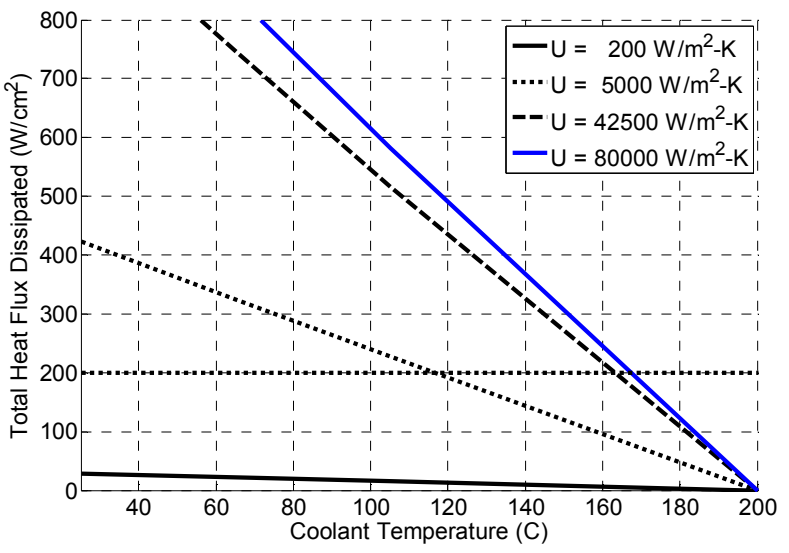

Fig. 13. Heat dissipation for the single-sided IHS package configuration with a maximum junction temperature of $200^{\circ} \mathrm{C}$ as a function of bulk coolant temperature and convection coefficient.

Figs. 14 and 15 show the heat dissipation capability of the one-sided DBSC configuration with $125^{\circ} \mathrm{C}$ and $200^{\circ} \mathrm{C}$ maximum junction temperatures, respectively. Even the advanced concepts such as DBSC and IHS with very aggressive convective heat transfer conditions cannot meet the $200 \mathrm{~W} / \mathrm{cm}^{2}$ target heat flux over the IGBT and diode with coolant temperatures of $105^{\circ} \mathrm{C}$ or higher and a maximum junction temperature of $125^{\circ} \mathrm{C}$. Also, effective convective heat transfer coefficients of about $5,000 \mathrm{~W} / \mathrm{m}^{2}-\mathrm{K}$ will be required even at a junction temperature of $200^{\circ} \mathrm{C}$. Double-sided cooling designs (not explicitly shown) would double the heat dissipation capability of the one-sided designs per the assumptions in this analysis. Moving to a double-sided design on an advanced concept such as IHS or DBSC together with an aggressive convective heat transfer condition may enable us to meet the $200 \mathrm{~W} / \mathrm{cm}^{2}$ cooling target, though more analysis is needed.

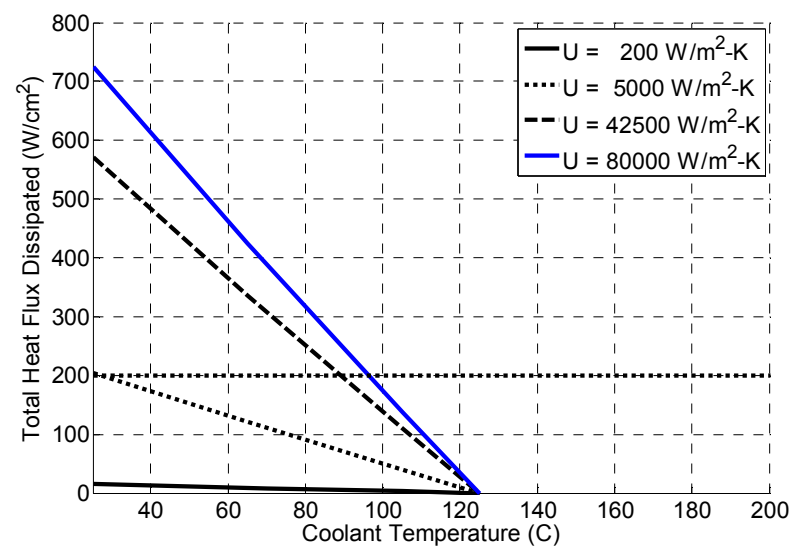

Fig. 14. Heat dissipation for the single-sided DBSC package configuration with a maximum junction temperature of $125^{\circ} \mathrm{C}$ as a function of bulk coolant temperature and convection coefficient.

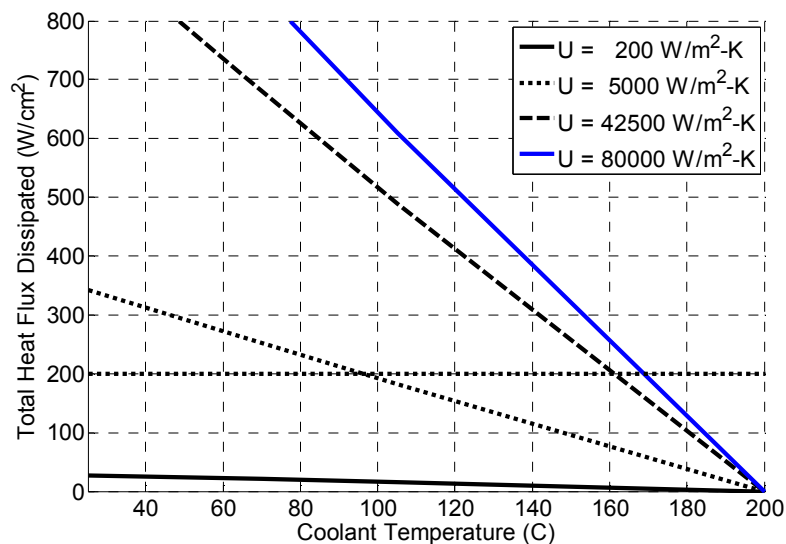

Fig. 15. Heat dissipation for the single-sided DBSC package configuration with a maximum junction temperature of $200^{\circ} \mathrm{C}$ as a function of bulk coolant temperature and convection coefficient.

Table V depicts heat flux dissipation sensitivity coefficients for the main factors that have been considered in this study. The sensitivity coefficients are the slopes of a marginal means plot and normalized by a $100 \%$ range and can be derived by the following equation [7]:

$$
S C_{f}=\frac{\overline{\dot{q}^{\prime \prime}\left(f_{h}\right)}-\overline{\dot{q}^{\prime \prime}\left(f_{l}\right)}}{100 \%}
$$

where $S C_{f}$ is the sensitivity coefficient for factor $f, q$ " is the heat flux dissipation, $f_{h}$ is the highest value of the given factor, and $f_{l}$ is the lowest value of the given factor. The difference between the average value of heat flux dissipation when the factor is at a high level is subtracted from the average heat flux dissipation when the factor is at a low level. This difference is divided by $100 \%$ to normalize the range over which we are varying the factors.

We can easily compare values for the same sensitivity coefficient between package designs. In general, we see that the IHS and DBSC designs can make better use of changes in junction temperature, coolant temperature, and effective heat transfer coefficient, than the baseline. Furthermore, we see that the DBSC concept can better use effective convection heat transfer coefficients than the IHS, and the IHS shows a better receptiveness to double-sided cooling. These results are in line with what we saw visually in Figs. 7 to 9. The TIM resistance for the BL model is on the same order per percent change as the other factors considered. Considering what can practically be changed for the baseline design, the TIM resistance represents a significant opportunity. 
TABLE V

HeAt Flux Dissipation SENSITIVITy COEFFICIENTS

\begin{tabular}{|c|c|c|c|}
\hline Heat Flux Increase $\left(\mathrm{W} / \mathrm{cm}^{2}\right)$ per: & BL & IHS & DBSC \\
\hline $1 \%$ increase in additional side area & 1.08 & 1.61 & 1.56 \\
\hline $\begin{array}{c}1 \% \text { increase in effective heat transfer } \\
\text { coefficient }\end{array}$ & 0.82 & 1.66 & 1.99 \\
\hline $1 \%$ increase in coolant temperature & -0.96 & -1.44 & -1.40 \\
\hline $1 \%$ increase in junction temperature & 0.89 & 1.31 & 1.27 \\
\hline $\begin{array}{c}1 \% \text { change in TIM thermal } \\
\text { resistance }\end{array}$ & -0.47 & NA & NA \\
\hline
\end{tabular}

\section{CONCLUSION}

In conclusion, this study explored how variations in inverter thermal package design, coolant temperature, the number of sides available for cooling, the maximum tolerable junction temperature, TIM thermal resistance, and effective convection coefficient affect cooling performance. Heat dissipation of 200 $\mathrm{W} / \mathrm{cm}^{2}$ over IGBT and diode surface areas may be possible with coolant temperatures of $105^{\circ} \mathrm{C}$ and above, coupled with a maximum junction temperature of only $125^{\circ} \mathrm{C}$ using advanced package designs (IHS or DBSC) with double-sided cooling and an aggressive heat transfer coefficient. Further investigation is needed. According to the set of cooling technologies investigated, no single-sided cooling solutions could dissipate the $200 \mathrm{~W} / \mathrm{cm}^{2}$ FreedomCAR target heat flux using $105^{\circ} \mathrm{C}$ coolant and a maximum junction temperature of $125^{\circ} \mathrm{C}$.

The heat dissipation rates are more sensitive to changes in the factors for the IHS and DBSC concepts than is the baseline. For the baseline configuration, there is a high sensitivity to changes in thermal resistance of the TIMs.

The double-sided packaging concept shows significant potential to increase heat dissipation. Although double-sided cooling receives only an initial treatment in this study, the potential indicates this concept should be further investigated. The IHS and DBSC concepts show the greatest potential.

As the convection coefficient increases, the thermal spreading in the heat sink seems to be less significant when the DBSC is compared to the IHS concepts. Thus, a smaller area DBSC could be used with nearly the same performance as a larger area DBSC concept.

Even with a junction temperature tolerance of $200^{\circ} \mathrm{C}$, free convection does not appear to be an option for cooling rates of $200 \mathrm{~W} / \mathrm{cm}^{2}$ over the IGBT and diode surface areas for a single die. Thus, NREL's investigations of air cooling focus on forced convection. Advanced air cooling concepts that use significant area enhancement and cooler outside air temperatures (as opposed to underhood temperatures) show potential to meet the heat flux dissipation goal.

This work is a first step in exploring various inverter package designs and configurations. The upper limit on convective heat transfer was set to $80,000 \mathrm{~W} / \mathrm{m}^{2}-\mathrm{K}$ for this work. However, even higher heat transfer coefficients are theoretically possible. Future work should further examine this potential. Additionally, the implications of thermal designs on inverter system cost, reliability, weight, and volume must be addressed. Furthermore, this study explored only a small number of general package design concepts; its objective was to map the cooling design space as a function of key factors. Further exploration of additional package designs coupled with more detailed simulation and optimization of each package configuration should be conducted.

\section{ACKNOWLEDGMENT}

This research effort was funded by the Department of Energy (DOE), Office of FreedomCAR and Vehicle Technologies. The authors would like to express their appreciation to Susan Rogers of the Office of FreedomCAR and Vehicle Technologies for her support on this project.

\section{REFERENCES}

[1] Y. Sakai, H. Ishiyama, and T. Kikuchi. Power control unit for high power hybrid system. Society of Automotive Engineers World Congress, April 16-19, 2007, Detroit, MI. SAE Paper 2007-01-0271.

[2] J. Hsu, R. Staunton, and M. Starke. Barriers to the Application of HighTemperature Coolants in Hybrid Electric Vehicles. Oak Ridge National Laboratory Technical Report ORNL/TM-2006/514, 2006.

[3] FreedomCAR and Fuels Partnership, Electrical and Electronics Technical Team Roadmap. Available: http://www1.eere.energy.gov/vehiclesandfuels/pdfs/program/eett_roadm ap.pdf. Accessed November 2006,

[4] B. Ozpineci, L.M. Tolbert, S.K. Islam, and M. Hasanuzzaman, Effects of silicon carbide $(\mathrm{SiC})$ power devices on PWM inverter losses, The 27th Annual Conference of the IEEE Industrial Electronics Society, November 29 - December 2, 2002, Denver, Colorado, pp. 1061-1066.

[5] K. Shenai, R.S. Scott, and B.J. Baliga, Optimum semiconductors for high-power electronics, IEEE Transactions on Electric Devices, vol. 43, no: 9, pp. 1811-1823, September 1989.

[6] F. Incropera and D. DeWitt, Fundamentals of Heat and Mass Transfer, $3^{\text {rd }}$ Edition, John Wiley and Sons, New York, Table 1.1 page 9, 1990.

[7] S.R. Schmidt and R.G. Launsby, Understanding Industrial Designed Experiments, 4th Edition. Colorado Springs, CO: Air Academy Press, 2000. 


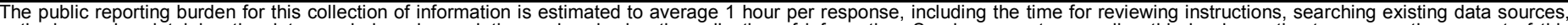

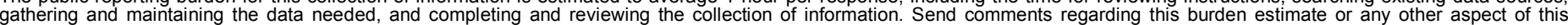

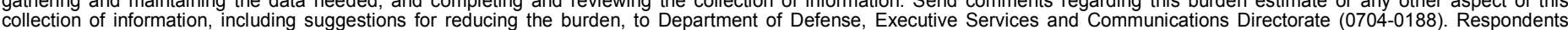

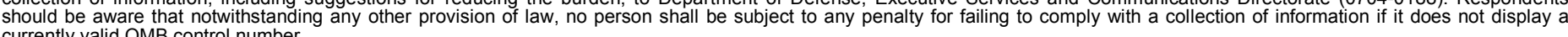

PLEASE DO NOT RETURN YOUR FORM TO THE ABOVE ORGANIZATION.
1. REPORT DATE (DD-MM-YYYY) January 2008
2. REPORT TYPE
Conference Paper
4. TITLE AND SUBTITLE
Comparison of Hybrid Electric Vehicle Power Electronics Cooling Options

3. DATES COVERED (From - To)

5a. CONTRACT NUMBER

DE-AC36-99-GO10337

5b. GRANT NUMBER

5c. PROGRAM ELEMENT NUMBER

5d. PROJECT NUMBER

NREL/CP-540-41886

5e. TASK NUMBER

FC077000

5f. WORK UNIT NUMBER

\section{PERFORMING ORGANIZATION NAME(S) AND ADDRESS(ES)}

National Renewable Energy Laboratory

1617 Cole Blvd.

Golden, CO 80401-3393

\author{
8. PERFORMING ORGANIZATION \\ REPORT NUMBER \\ NREL/CP-540-41886
}

9. SPONSORING/MONITORING AGENCY NAME(S) AND ADDRESS(ES) 10. SPONSOR/MONITOR'S ACRONYM(S)
NREL

11. SPONSORING/MONITORING AGENCY REPORT NUMBER

12. DISTRIBUTION AVAILABILITY STATEMENT

National Technical Information Service

U.S. Department of Commerce

5285 Port Royal Road

Springfield, VA 22161

13. SUPPLEMENTARY NOTES

14. ABSTRACT (Maximum 200 Words)

This study quantifies the heat dissipation potential of three inverter package configurations over a range of control factors. These factors include coolant temperature, number of sides available for cooling, effective heat transfer coefficient, maximum semiconductor junction temperature, and interface material thermal resistance. Heat dissipation potentials are examined in contrast to a research goal to use $1050 \mathrm{C}$ coolant and dissipate $200 \mathrm{~W} / \mathrm{cm} 2 \mathrm{heat}$ across the insulated gate bipolar transistor and diode silicon area. Advanced double-sided cooling configurations with aggressive heat transfer coefficients show the possibility of meeting these targets for a $1250 \mathrm{C}$ maximum junction temperature, but further investigation is needed. Even with maximum tolerable junction temperatures of $2000 \mathrm{C}$, effective heat transfer coefficients of 5,000 to $10,000 \mathrm{~W} / \mathrm{m} 2-\mathrm{K}$ will be needed for coolant temperatures of $1050 \mathrm{C}$ or higher.

\section{SUBJECT TERMS}

hybrid electric vehicle; power electronics; heat dissipation potential; inverter package

\begin{tabular}{|c|c|c|c|c|}
\hline \multicolumn{3}{|c|}{ 16. SECURITY CLASSIFICATION OF: } & \multirow{2}{*}{$\begin{array}{l}\text { 17. LIMITATION } \\
\text { OF ABSTRACT } \\
\text { UL }\end{array}$} & \multirow{2}{*}{$\begin{array}{l}\text { 18. NUMBER } \\
\text { OF PAGES }\end{array}$} \\
\hline $\begin{array}{l}\text { a. REPORT } \\
\text { Unclassified }\end{array}$ & $\begin{array}{l}\text { b. ABSTRACT } \\
\text { Unclassified }\end{array}$ & $\begin{array}{l}\text { c. THIS PAGE } \\
\text { Unclassified }\end{array}$ & & \\
\hline
\end{tabular}

19a. NAME OF RESPONSIBLE PERSON
19b. TELEPHONE NUMBER (Include area code)

